\title{
Effect of Different Host Plants on Growth, Development and Reproduction of Yellow Tortrix Moth Acleris fimbriana (Lepidoptera: Tortricidae)
}

\author{
Yonghua Liu*, Xianhua Li, Xiongfei Yan and Gang Li \\ Key Laboratory of Ecological Restoration in Shanbei Mining Area, and Key Laboratory \\ of Plant Pest Control in Yulin City, Yulin University, Yulin 719000, P. R. China
}

\begin{abstract}
A B S T R A C T
The yellow tortrix, Acleris fimbriana Merick (Lepidoptera: Tortricidae), is a serious pest on fruit trees in North China. Under laboratory conditions (temperature $25 \pm 1^{\circ} \mathrm{C}, 80 \pm 5 \%$ relative humidity, photoperiod 14L:10D), the effect of the 4 host plants Armeniaca vulgaris (apricot), Malus pumila (apple), Prunus salicina (plum), and Amygdalus persica (peach) on the growth, development, survival, reproduction, and life table parameters of $A$. fimbriana were studied. Different host plants had significant effects on the growth, development, and reproduction of A. fimbriana. The overall developmental duration was the longest on apple $(60.71 \mathrm{~d})$ and peach $(60.78 \mathrm{~d})$ and shortest on apricot $(54.55 \pm 3.56 \mathrm{~d})$. The cumulative survival rate was highest on apricot $(64.58 \%)$ and plum $(60.44 \%)$ and lowest on peach $(44.50 \%)$. The average number of eggs produced was highest on apricot (175.58 eggs) and plum (178.43 eggs). Life table parameter results showed that the net reproductive rate, intrinsic growth rate, and finite growth rate were highest on apricot $(101.75,0.0892$, and 1.0933, respectively) and plum $(97.75,0.0832$, and 1.0867, respectively). Mean generation time was the longest on apple $(58.41 \mathrm{~d})$ and peach $(58.45 \mathrm{~d})$. Population doubling time was shortest on apricot $(7.77 \mathrm{~d})$ and plum $(8.33 \mathrm{~d})$. Of the 4 hosts, apricot and peach are more suitable for $A$. fimbriana growth, development, and reproduction. The results of this study provide an important basis for forecasting and integrated management of $A$. fimbriana.
\end{abstract}

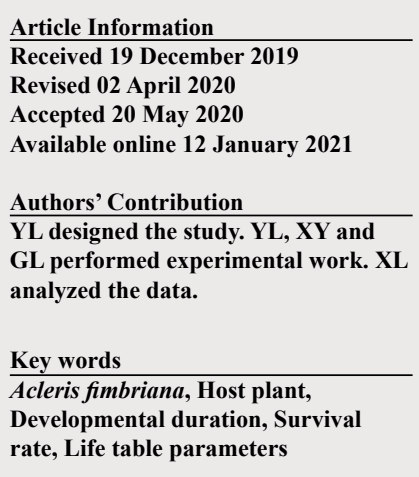

Article Information

Revised 02 April 2020

Accepted 20 May 202

Available online 12 January 202

Authors' Contribution

YL designed the study. YL, XY and

GL performed experimental work. XL

analyzed the data.

Key words

Developmental duration, Surviva

rate, Life table parameters

\section{INTRODUCTION}

$\mathrm{T}$ he yellow tortrix moth, Acleris fimbriana (Merick) (Lepidoptera: Tortricidae) distributed over a wide range with many types of hosts. Currently, its main host plants include apple, peach, pear, plum, apricot, hawthorn, birchleaf pear, and others (Ma, 1997). The larvae of $A$. fimbriana harm leaves by causing them to curl and stop growing, ultimately causing clusters of leaves to curl into a mass and severely decreasing the yield of fruit trees and the quality of fruit (Ma et al., 2000; Li et al., 2005). Thus, A. fimbriana is one of the most important pests of fruit trees in northern China.

Factors, such as temperature, humidity, light, and sources of food, are important ecological factors affecting insect growth and development. Of these, the foodrelated factors are the most important (Sun et al., 2015). Herbivorous insects must rely on basic nutrients provided by a host to survive, but they must also obtain food from different hosts. Because different hosts contain different

\footnotetext{
* Corresponding author: liuyonghuaa@126.com 0030-9923/2021/0002-0475 \$9.00/0

Copyright 2021 Zoological Society of Pakistan
}

nutrients and secondary biomass, they affect the growth, development, survival and reproduction of insects in different ways (Kim and Lee, 2002; Razmjou et al., 2014). Sun et al. (2015b) found that the developmental duration, generation survival rate, fecundity, intrinsic growth rate, and other indices of Adoxophyes orana growing on peach, apple, plum, and apricot differed significantly. Saeed et al. (2010) also found that Canola and mustard are the most suitable hosts for Plutella xylostella because of the shorter developmental period, higher percentage of survival and higher number of eggs. Initiating studies on the effects of different hosts on pests will allow researchers to understand more deeply the patterns and population dynamics by which pests attack different hosts and provide a basis for developing rational preventive measures (Karungi et al., 2010; Andrade et al., 2016; Li et al., 2014).

Currently, the bioecological characteristics of $A$. fimbriana have been elucidated (Han et al., 1996; Ma et al., 2000; Zhang, 2011; Liu et al., 2019). The field efficacy of several pestcides have been proved to be better (Zhang et al., 2011). The adult female sex pheromone has been widely studied, included component, location, ultrastructure and field trapping (Ma and Liu, 1993; Ma, 1997; Liu and Meng, 2002, 2003; Zhao et al., 2016). However, there 
are only few studies on the effects of different hosts on its growth, development, and reproduction. Thus, this study selected 4 representative host plants in the same region and systematically studied the effect of different host plants on the growth, development, survival, reproduction, and other biological properties of $A$. fimbriana to obtain a better understanding of the patterns of its growth and development and provide a scientific basis for forecasting and management.

\section{MATERIALS AND METHODS}

\section{Hosts to be tested}

Previous field investigations revealed that apricot (Armeniaca vulgaris), apple (Malus pumila), plum (Prunus salicina) and peach (Amygdalus persica), four fruit trees planted in the mountainous area of northern Shaanxi, are commonly damaged by $A$. fimbriana to different extents. Thus, these four fruit trees were selected as the host plants to be tested, and fresh leaves that had not been treated with pesticides were picked for testing.

\section{Insect sources to be tested}

A. fimbriana larvae growing on the four hosts mentioned above were collected and placed in an artificial climate chamber for rearing. The conditions in the artificial climate chamber were set to a photoperiod of $14 \mathrm{~L}: 10 \mathrm{D}$, a temperature of $25 \pm 1^{\circ} \mathrm{C}$, and relative humidity of $80 \pm$ $5 \%$. Fresh leaves from the four hosts were collected and separately fed to the corresponding larvae. After pupation and eclosion, adult females and males that were grown on the same host and eclosed on the same day were paired in cages and freely allowed to mate and lay eggs. Eggs were collected for subsequent experiments within $6 \mathrm{~h}$ of laying.

\section{Observations of developmental duration}

After eggs were laid by adults, the first eggs were collected, cleared of debris, gently placed on a piece of gauze using a brush, and placed in a culture dish (diameter $7 \mathrm{~cm}$ ). 100 eggs in triplicate were used for each condition were incubated in an artificial climate chamber as previously described. Observations were made three times, at 8:00, 16:00, and 24:00 daily. The hatching status of the eggs was observed and the duration of the egg stage was recorded.

After hatching, individual newly hatched larvae were immediately placed in plastic bottles (height 20 $\mathrm{cm}$, diameter $10 \mathrm{~cm}$ ). Fresh leaves were replenished every day at fixed intervals. 30 bottles in triplicate were used for each condition and placed in an artificial climate chamber. Observations of larval development status were made three times, at 8:00, 16:00, and 24:00 daily until the larvae matured. The survival rate, developmental duration, and other parameters of the larvae were recorded. After pupation, the pupal duration was recorded. After eclosion, the eclosion rate, longevity, and developmental duration of the adults were recorded.

\section{Observations of mating and oviposition in adults}

Male and female adults grown on the same host and that eclosed on the same day were paired. Each pair were placed in a plastic cup (height $20 \mathrm{~cm}$, diameter $10 \mathrm{~cm}$ ) with the top covered with gauze, which was then placed in an artificial climate chamber. 20 bottles in triplicate were used for each condition. For 5 consecutive days, the number of mating was observed every 30 min during the dark period (18:00 - 6:00 of the next day). Finally, observations of the survival, oviposition, and other events were made three times, at 8:00, 16:00, and 24:00 daily. Oviposition duration, fecundity, and other data were recorded until the insects died.

\section{Data analyses and statistics}

The method of Zhang (2002) was used for population life table parameters, where the net reproductive rate $R_{0}$ $=\Sigma l_{x} m_{x}$, mean generation time $T=\Sigma x l_{x} m_{x} / R_{0}$, intrinsic growth rate $r_{m}=\ln R_{0} / T$, finite growth rate $\lambda=e^{r m}$, and population doubling time $D_{t}=\ln 2 / r_{m}$. In the equation, $l_{x}$ is the probability of survival for a given individual during a time period $x$, and $m_{x}$ is the average number of females produced per female during a time period $x$.

After using analysis of variance (ANOVA) to analyze the developmental duration, survival, fecundity, longevity, and other data of $A$. fimbriana grown with different hosts, Duncan's new multiple range test was used to analyze the significance of the differences.

\section{RESULTS}

\section{Effect of different host plants on the duration of different developmental stages}

Table I shows the effect of feeding on different host plants on the duration of different developmental stages of A. fimbriana. A. fimbriana can complete its life cycle normally when fed with all 4 types of host plants, but there are differences in the duration of each developmental stage. The egg duration was the shortest on apricot at 8.33 $\pm 1.26 \mathrm{~d}$, which was significantly lower than that on the other hosts $(p<0.05)$. However, the egg duration on apple, plum, and peach did not differ significantly $(p>0.05)$. The larval duration was shortest on plum at $25.35 \pm 3.58 \mathrm{~d}$, but this was not significantly different from that on apricot $(p>0.05)$. The larval duration was longest on peach at $27.15 \pm 2.06 \mathrm{~d}$, but this was not significantly different 
from that on apple $(p>0.05)$. However, the larval duration on plum and apricot showed a significant difference $(p<$ $0.05)$ when compared with those on peach and apple. $A$. fimbriana larvae fed with different host plants did not result in a significant difference in pupal duration. However, an integrated comparison of all developmental durations from egg to larva to pupa showed that the developmental duration gradually increased from apricot to plum to peach to apple, at $44.97 \pm 2.68 \mathrm{~d}, 46.72 \pm 2.55 \mathrm{~d}, 48.31$ $\pm 3.12 \mathrm{~d}$, and $48.33 \pm 3.05 \mathrm{~d}$, respectively. Furthermore, the developmental durations on the peach and apple trees were significantly higher than those on the apricot and plum trees $(p<0.05)$. Feeding on different hosts has a significant effect on the longevity of $A$. fimbriana adults. Adults fed on peach had the greatest average longevity at $12.45 \pm 2.36 \mathrm{~d}$; those fed on apricot had the shortest longevity at $9.54 \pm 1.88 \mathrm{~d}$. The developmental duration of the entire generation was the longest in A. fimbriana fed on apple and peach with no significant difference between the two, but both were significantly longer than that fed on apricot and plum.

Table I also shows that for any given host, the duration of the larval stage was the longest of all of the developmental stages in $A$. fimbriana, followed by the pupal stage, with the egg stage being the shortest.

\section{Effect of different host plants on A. fimbriana developmental status}

Table II shows the effects of different host plants on the developmental status of each developmental stage of A. fimbriana. Table II shows that the egg hatching rate did not differ significantly between $A$. fimbriana fed on apricot, apple, plum, and peach hosts, reaching $83.45 \%$, $82.75 \%, 82.43 \%$, and $83.24 \%$, respectively. The pupation rate of larvae was also close between the groups, at $95.24 \%, 96.43 \%, 95.65 \%$, and $94.54 \%$, respectively. The eclosion rates of pupae were higher on apricot, apple, and plum at $96.38 \%, 95.45 \%$, and $96.25 \%$, respectively, but the difference was not significant. The eclosion rate on peach was the lowest at $90.65 \%$, significantly lower than that on the other three hosts $(p<0.05)$.

After feeding on different hosts, the survival rate of larvae on apricot leaves was the highest at $84.31 \%$, followed by plum at $79.64 \%$, apple at $68.45 \%$, and peach at $62.38 \%$ with the lowest survival rate; the difference between the four hosts was significant $(p<0.05)$. Since the difference in larval survival rate was significant, the cumulative survival rate of $A$. fimbriana on the four hosts was also significantly different. The cumulative survival rate on apricot and plum was significantly higher than those on apple and peach $(p<0.05)$.

Besides, larvae that fed on plum had the highest pupal weight at $25.43 \pm 2.08 \mathrm{mg}$, followed by apricot at $22.35 \pm$ $1.68 \mathrm{mg}$. The pupal weights for larvae that fed on apple and peach were the lowest, at $20.48 \pm 2.36 \mathrm{mg}$ and $20.75 \pm$ $1.85 \mathrm{mg}$, respectively.

Effect of different host plants on A. fimbriana reproduction Different host plants have significant effects on $A$. fimbriana oviposition and mating (Table III). Adults with plum as the host had the longest oviposition duration at $6.23 \pm 0.78 \mathrm{~d}$, and adults with peach as the host had the

Table I. The developmental duration (d) of $A$. fimbriana on different host plants.

\begin{tabular}{llllll}
\hline Host plants & Egg duration (d) & Larva duration (d) & Pupa duration (d) & Adult longevity (d) & Generation duration(d) \\
\hline Apricot & $8.33 \pm 1.26 \mathrm{~b}$ & $25.46 \pm 2.86 \mathrm{~b}$ & $11.35 \pm 2.12 \mathrm{a}$ & $9.64 \pm 1.88 \mathrm{bc}$ & $54.55 \pm 3.56 \mathrm{c}$ \\
Apple & $10.18 \pm 2.05 \mathrm{a}$ & $26.86 \pm 2.34 \mathrm{a}$ & $11.44 \pm 2.26 \mathrm{a}$ & $12.32 \pm 2.54 \mathrm{a}$ & $60.71 \pm 3.76 \mathrm{a}$ \\
Plum & $10.25 \pm 1.68 \mathrm{a}$ & $25.35 \pm 3.58 \mathrm{~b}$ & $11.28 \pm 1.83 \mathrm{a}$ & $10.22 \pm 1.35 \mathrm{~b}$ & $56.85 \pm 4.11 \mathrm{~b}$ \\
Peach & $9.93 \pm 2.14 \mathrm{a}$ & $27.15 \pm 2.06 \mathrm{a}$ & $11.39 \pm 1.65 \mathrm{a}$ & $12.45 \pm 2.36 \mathrm{a}$ & $60.78 \pm 3.85 \mathrm{a}$ \\
\hline
\end{tabular}

The dates in the table are mean $\pm \mathrm{SE}$, the letters after them are the results of multi comparison. Different letters in the same column means significant difference by Duncan's multiple range test $(P<0.05)$.

Table II. Development states of Acleris fimbriana on different host plants.

\begin{tabular}{lllllll}
\hline Host plants & $\begin{array}{l}\text { Egg hatchability } \\
(\%)\end{array}$ & $\begin{array}{l}\text { Survival rate of } \\
\text { larvae (\%) }\end{array}$ & $\begin{array}{l}\text { Pupation rate } \\
(\%)\end{array}$ & $\begin{array}{l}\text { Pupal weight (mg) } \\
(\%)\end{array}$ & $\begin{array}{l}\text { Emergence } \\
\text { rate (\%) }\end{array}$ & $\begin{array}{l}\text { Total survival } \\
\text { rate (\%) }\end{array}$ \\
\hline Apricot & $83.45 \mathrm{a}$ & $84.31 \mathrm{a}$ & $95.24 \mathrm{a}$ & $22.35 \pm 1.68 \mathrm{~b}$ & $96.38 \mathrm{a}$ & $64.58 \mathrm{a}$ \\
Apple & $82.75 \mathrm{a}$ & $68.45 \mathrm{c}$ & $96.43 \mathrm{a}$ & $20.48 \pm 2.36 \mathrm{c}$ & $95.45 \mathrm{a}$ & $52.14 \mathrm{~b}$ \\
Plum & $82.43 \mathrm{a}$ & $79.64 \mathrm{~b}$ & $95.65 \mathrm{a}$ & $25.43 \pm 2.08 \mathrm{a}$ & $96.25 \mathrm{a}$ & $60.44 \mathrm{a}$ \\
Peach & $83.24 \mathrm{a}$ & $62.38 \mathrm{~d}$ & $94.54 \mathrm{a}$ & $20.75 \pm 1.85 \mathrm{c}$ & $90.65 \mathrm{~b}$ & $44.50 \mathrm{c}$ \\
\hline
\end{tabular}


Table III. Fecundity of Acleris fimbriana on different host plants.

\begin{tabular}{llllll}
\hline Host plants & Preoviposition duration (d) Oviposition duration (d) & Number of eggs laid Oviposition rate (\%) & Mating rate (\%) \\
\hline Apricot & $2.15 \pm 0.65 \mathrm{a}$ & $6.12 \pm 0.55 \mathrm{a}$ & $175.58 \pm 23.15 \mathrm{a}$ & $100 \mathrm{a}$ & $96.55 \mathrm{a}$ \\
Apple & $2.26 \pm 0.44 \mathrm{a}$ & $5.21 \pm 1.02 \mathrm{~b}$ & $155.33 \pm 21.24 \mathrm{~b}$ & $100 \mathrm{a}$ & $82.56 \mathrm{~b}$ \\
Plum & $2.08 \pm 0.38 \mathrm{a}$ & $6.23 \pm 0.78 \mathrm{a}$ & $178.43 \pm 25.35 \mathrm{a}$ & $100 \mathrm{a}$ & $95.22 \mathrm{a}$ \\
Peach & $2.21 \pm 0.62 \mathrm{a}$ & $5.17 \pm 0.88 \mathrm{~b}$ & $158.42 \pm 22.31 \mathrm{~b}$ & $100 \mathrm{a}$ & $85.68 \mathrm{~b}$ \\
\hline
\end{tabular}

Table IV. Population dynamic parameters of Acleris fimbriana on different host plants.

\begin{tabular}{llllll}
\hline Host plants & $\begin{array}{l}\text { Net reproductive } \\
\text { rate }\left(\boldsymbol{R}_{\boldsymbol{p}}\right)\end{array}$ & $\begin{array}{l}\text { Mean generation } \\
\text { time }(\boldsymbol{T})\end{array}$ & $\begin{array}{l}\text { Intrinsic rate of } \\
\text { increase }\left(\boldsymbol{r}_{\boldsymbol{m}}\right)\end{array}$ & $\begin{array}{l}\text { Finite rate of } \\
\text { increase }(\boldsymbol{\lambda})\end{array}$ & $\begin{array}{l}\text { Doubling time } \\
(\boldsymbol{D})_{\boldsymbol{t}}\end{array}$ \\
\hline Apricot & $101.75 \pm 6.78 \mathrm{a}$ & $51.82 \pm 0.52 \mathrm{bc}$ & $0.0892 \pm 0.0045 \mathrm{a}$ & $1.0933 \pm 0.0021 \mathrm{a}$ & $7.77 \mathrm{a}$ \\
Apple & $75.59 \pm 4.85 \mathrm{~b}$ & $58.41 \pm 0.46 \mathrm{a}$ & $0.0741 \pm 0.0032 \mathrm{~b}$ & $1.0768 \pm 0.0026 \mathrm{~b}$ & $9.36 \mathrm{~b}$ \\
Plum & $97.75 \pm 5.14 \mathrm{a}$ & $55.07 \pm 0.51 \mathrm{~b}$ & $0.0832 \pm 0.0051 \mathrm{a}$ & $1.0867 \pm 0.0035 \mathrm{a}$ & $8.33 \mathrm{a}$ \\
Peach & $64.98 \pm 3.65 \mathrm{~b}$ & $58.45 \pm 1.03 \mathrm{a}$ & $0.0714 \pm 0.0038 \mathrm{~b}$ & $1.0740 \pm 0.0041 \mathrm{~b}$ & $9.70 \mathrm{~b}$ \\
\hline
\end{tabular}

shortest oviposition duration at $5.17 \pm 0.88 \mathrm{~d}$. ANOVA results showed that oviposition duration for $A$. fimbriana that fed on plum and apricot was significantly longer than that on apple and peach. The average number of eggs laid differed significantly between the different hosts. Larvae that fed on plum and apricot produced a significantly higher number of eggs, $178.43 \pm 25.35$ and $175.58 \pm 23.15$ eggs, respectively, upon reaching adulthood than those on the other hosts. The pre-oviposition duration did not differ significantly between female adults fed with different host plants; in addition, the oviposition rate reached $100 \%$ for all host plants.

The mating rate of $A$. fimbriana that fed on different host plants did not differ significantly. The mating rate of adults that fed on apricot and plum as larvae was $96.55 \%$ and $95.22 \%$, respectively, which was higher than the mating rate of those that fed on apple and peach.

Population life table parameters of A. fimbriana fed with different hosts

The survival rate and fecundity of different stages of A. fimbriana fed with different host plants were used to construct an age-specific life table and calculate population life table parameters. As shown in Table IV, A. fimbriana with apricot as the host had the highest net reproductive rate, intrinsic growth rate, and finite growth rate and the lowest mean generation time and population doubling time. There was no significant difference in the above indices with plum as the host, but they were significantly higher than when apple or peach were the hosts. Thus, apricot and peach are more suitable for the growth, development, and reproduction of $A$. fimbriana, whereas apple and peach are relatively less suitable.

\section{DISCUSSION}

Because the leaves of different host plants have different physiological and chemical properties, they affect the growth, development, and reproduction of insects to different extents (Chen et al., 2011). This study found that four host plants - apricot, apple, plum, and peach have significant effects on the growth, development, and reproduction of Acleris fimbriana. Of these, developmental duration was shortest with apricot as the host, survival rate, number of eggs laid, and mating rate were highest with apricot or plum as the host, net reproductive rate, intrinsic growth rate, and finite growth rate were relatively high with apricot or plum as the host, and population doubling time was relatively long with apple or peach as the host, showing that $A$. fimbriana populations are best adapted to survive and reproduce on apricot or plum trees. Thus, these two types of trees should be monitored more closely when predicting and forecasting pests. However, the results of this study are relative, as there have been studies showing that $A$. fimbriana caused relatively severe damage to peach and apple trees in Taigu County, Shanxi Province by (Ma et al., 2000) and peach and apricot trees in Kuqa County, Xinjiang (Zhang, 2011; Zhang et al., 2011b). This may be due to regional differences in local host tree species and distribution. Previous studies have shown that in the apricot planting area of northern Shaanxi, A. fimbriana caused relatively severe damage to apricot and plum trees, whereas the damage to peach and apple trees was relatively mild, which is consistent with the findings of this study.

There have been studies showing that lepidopteran insects feeding on different host plants have higher survival rate and number of eggs laid as larval duration decreases; 
conversely, with increased larval duration, survival rate and number of eggs laid decreases (Greenberg et al., 2001; Nabi et al., 2007; Shahout et al., 2011; Zhang et al., 2011b; Farahani et al., 2011; Yang et al., 2016). The results of the present study confirm this finding, showing that shortened larval duration benefits the survival and reproduction of the insect population. Our results show that when plum was the host, A. fimbriana pupal weight was significantly higher than for the other hosts. Besides, the average number of eggs laid by the adult was also the highest, showing that it had increased fecundity and that under appropriate conditions, plum is more appropriate for the growth and development of $A$. fimbriana. However, there has currently not been many reports of damage to plum trees by $A$. fimbriana. Thus, in regions with plum trees planted in larger areas, A. fimbriana monitoring and management should be enhanced to prevent damage over large areas.

Using life table studies of insect population dynamics to optimize pest management has become the most important technique in insect research (Kakde et al., 2014). Net reproductive rate, intrinsic growth rate, finite growth rate, and population doubling time are important indices for assessing the biological properties of insect populations, but the effect on population growth is different (Krips et al., 1998; Tsai et al., 2001). The results of the present study show that the cumulative survival rate of A. fimbriana on apricot and plum is $64.58 \%$ and $60.44 \%$, the average number of eggs laid is $175.58 \pm 23.15$ and $178.43 \pm 25.35$, respectively. There is no significant difference between the two, which means that the life table parameters of A. fimbriana on these two hosts also do not differ significantly, showing that the degree of harm caused by $A$. fimbriana to apricot and plum trees is generally similar. Likewise, the degree of harm to apple and peach trees is generally similar.

Preventing damage to leaves caused by A. fimbriana larvae is relatively difficult, so the results of the present study provide an initial understanding of how $A$. fimbriana populations change on different host plants and a basis for forecasting and integrated management measures. However, the results of this study were obtained under artificially controlled conditions in a laboratory, and there are differences from actual natural conditions in the wild. In addition to hosts, different temperature, humidity, and light conditions are also important factors that affect insect growth, development, and reproduction. Thus, local conditions should be considered during pest prevention and taken together with the results of this study in order to achieve the best outcomes. In addition, further research is required to find other factors that affect A. fimbriana population growth.

\section{CONCLUSION}

In this work, we found that $A$. fimbriana populations are best adapted to survive and reproduce on apricot or plum trees. These two types of trees should be monitored more closely when predicting and forecasting pests. The results provide an important basis for forecasting and integrated management of $A$. fimbriana.

\section{ACKNOWLEDGMENTS}

This work was supported by the Natural Science Foundation of China (No. 31760209). We are grateful to all students and staff in the Key Laboratory of Ecological Restoration in Shanbei Mining Area and Plant Pest Control in Yulin City, Yulin University, Shaanxi, China for their assistance.

\section{Statement of conflict of interest}

The authors have declared no conflicts of interest.

\section{REFERENCES}

Andrade, K., Bueno, A.F., Silva, D.M., Stecca, C.S., Pasini, A. and Oliveira, M.C.N., 2016. Bioecological characteristics of Chrysodeixis includens (Lepidoptera: Noctuidae) fed on different hosts. Austral. Ent., 55: 449-454. https://doi.org/10.1111/aen.12208

Chen, Y.G., Ciaramitaro, T. and Poland, T.M., 2011. Moisture content and nutrition as selection forces for emerald ash borer larvae feeding behavior. Ecol. Ent., 36: 344-354. https://doi.org/10.1111/j.13652311.2011.01278.x

Farahani, S., Naseri, B. and Talebi, A.A., 2011. Comparative life table parameters of the beet armyworm, Spodoptea exigua (Hübner) (Lepidoptera: Noctuidae) on five host plants. $J$. Ent. Res. Soc., 13: 91-101.

Greenberg, S.M., Sappington, T.W., Legaspijr, B.C., Liu, T.X. and Setamou, M., 2001. Feeding and life history of Spodoptera exigua (Lepidoptera: Noctuidae) on different host plants. Annls entomol. Soc. Am., 94: 566-575. https://doi. org/10.1603/0013-8746(2001)094[0566:FALHOS ]2.0.CO;2

Han, G.B., Ma, R.Y. and Li, L.C., 1996. Study on adult biological characteristics of Acleris fimbriana (Lepidoptera: Tortricidae). Forest Pest. Dis., 1: 1214.

Kakde, A.M., Patel, K.G. and Shailesh, T., 2014. Role of life table ininsect pest management: A 
review. J. Agric. Vet. Sci., 7: 40-43. https://doi. org/10.9790/2380-07114043

Karungi, J., Lubanga, U.K., Kyamanywa, S. and Ekbom, B., 2010. Oviposition preference and offspring performance of Crocidolomia pavonana (Lepidoptera: Pyralidae) on different host plants. $J$. appl. Ent., 134: 704-713. https://doi.org/10.1111/ j.1439-0418.2010.01518.x

Kim, D.S. and Lee, J.H., 2002. Egg and larval survivorship of Carposina sasakii (Lepidoptera: Carposinidae) in apple and peach and their effects on adult population dynamics in orchards. Environ. Ent., 31: 686-692. https://doi.org/10.1603/0046225X-31.4.686

Krips, O.E., Witul, A., Willems, P.E.L. and Dicke, M., 1998. Intrinsic rate of population increase of the spider mite Tetranychus urticae on the ornamental crop gerbera: Intraspecific variation in host plant and herbivore. Ent. Exp. Appl., 89:159-168. https:// doi.org/10.1046/j.1570-7458.1998.00395.x

Li, D.Y., Ai, P.P., Du, Y.L., Sun, S.L. and Zhang, M.Z., 2014. Effects of different host plants on the development and reproduction of yellow peach moth, Conogethes punctiferalis (Guenée, 1854) (Lepidoptera: Crambidae). Austral. Entomol., 54: 149-153. https://doi.org/10.1111/aen.12105

Li, J., Zhao, F., He, R.P., Niu, R.S., Ma, R.Y. and Meng, X.Z., 2005. Effect of forecasting and trapping of sex pheromone in Acleris fimbriana (Lepidoptera: Tortricidae). J. Shanxi agric. Sci., 33: 64-66. https:// doi.org/10.3969/j.issn.1002-2481.2005.03.019

Liu, Y.H., Liu, J., Yan, X.F. and He, Y., 2019. Effects of temperature on the growth, development and reproduction of Acleris fimbriana (Lepidoptera: Tortricidae). J. Forest Environ., 39: 444-448. https://doi.org/10.13324/j.cnki.jfcf.2019.04.018

Liu, Y.X. and Meng, X.Z., 2002. Identification of sexpheromone components for Acleris fimbriana (Lepidoptera: Tortricidae). Can. Ent. 34: 511-518. https://doi.org/10.4039/Ent134511-4

Liu, Y.X. and Meng, X.Z., 2003.Trapping effect of synthetic sex pheromone of Acleris fimbriana (Lepidoptera: Tortricidae) in Chinese northern orchard. Z. Naturforsch. C., 58: 421-425. https:// doi.org/10.1515/znc-2003-5-622

Ma, R.Y., 1997. Preliminary studies on the sex pheromone biology of yellow tortrix, Acleris fimbriana (Lepidoptera: Tortricidae). J. Shanxi agric. Univ., 17: 339-341. https://doi.org/10.13842/j.cnki. issn1671-8151.1997.04.008

Ma, R.Y., Jing, Y., Li, Z., LI, Y.Q. and Zhang, Y.P., 2000. Study on behaviour and habits of yellow tortrix,
Acleris fimbriana (Lepidoptera: Tortricidae). J. Shanxi agric. Univ., 20: 20-23. https://doi. org/10.13842/j.cnki.issn1671-8151.2000.01.006

Ma, R.Y. and Li, L.C., 1993. An observation with scanning electron microscope on the surface of the sex gland of yellow totrix. J. Shanxi agric. Univ., 13: 318-320. https://doi.org/10.13842/j.cnki. issn1671-8151.1993.04.012

Nabi, A.K., Bahattin, K. and Bülen,t A., 2007. Life tables of the olive leaf moth, Palpita unionalis (Hübner) (Lepidoptera: Pyralidae), on different host plants. J. environ. Biol., 1: 105-110.

Razmjou, J., Naseri, B. and Ali, H.S., 2014. Comparative performance of the cotton bollworm, Helicoverpa armigera (Hübner) (Lepidoptera: Noctuidae) on various host plants. J. Pestic. Sci., 87: 29-37. https://doi.org/10.1007/s10340-013-0515-9

Saeed, R., Sayyed, A.H., Shad, S.A. and Zaka, S.M., 2010. Effect of different host plants on the fitness of diamond-back moth, Plutella xylostella (Lepidoptera: Plutellidae). Crop. Prot., 29: 178182. https://doi.org/10.1016/j.cropro.2009.09.012

Shahout, H.A., Xu, J.X., Yao, X.M. and Jia, Q.D., 2011. Influence and mechanism of different hostplants on the growth, development and fecundity of reproductive system of common cutworm, Spodoptera litura (Fabricius) (Lepidoptera: Noctuidae). Asian J. agric. Sci., 3: 291-300.

Sun, L.N., Qin, G.S., Zhang, H.G. and Yan, W.T., 2015. Growth development and reproduction of the summer fruit tortrix moth, Adoxophyes orana beijingensis (Lepidoptera: Tortricidae), on four host plants. Acta entomol. Sin., 58: 53-59. https:// doi.org/10.16380/j.kcxb.2015.01.007

Sun, L.N., Yan, W.T., Zhang, H.J. and Qiu, G.S., 2015 b. Development and reproduction of Adoxophyes orana on six apple varieties. Shandong agric. Sci., 47: 92-95,104. https://doi.org/10.14083/j. issn.1001-4942.2015.01.050

Tsai, J.H. and Wang, J.J., 2001. Effects of host plants on biology and life table parameters of Aphis spiraecola (Homoptera:Aphididae). Environ. Ent., 30: 45-50. https://doi.org/10.1603/0046225X-30.1.44

Yang, X.F., Fan, F., Ma, C.S., Wang, C. and Wei, G.S., 2016. Effect of host plants on the development, survivorship and reproduction of Grapholita molesta (Lepidoptera: Tortricidae) under laboratory conditions. Austral. Entomol., 55: 433-438. https:// doi.org/10.1111/aen.12204

Zhang, X.X., 2002. Insect ecology and forecast. 3rd ed. China Agriculture Press, Beijing, China. (in 
Chinese).

Zhang, B., Liu, H., Sanders, H.H. and Wang, J.J., 2011. Effect of host plants on development, fecundity and enzyme activity of Spodoptera exigua (Hübner) (Lepidoptera: Noctuidae). Agric. Sci. China, 10: 1232-1240. https://doi.org/10.1016/S16712927(11)60114-4

Zhang, R.F., 2011. Studies on spatial distribution and sampling techninques of Acleris fimbirana Thunberg larvae. Xinjiang agric. Sci., 48: 291-295.
Zhang, R.F., Wang, D.Y., Wang, H. and Yu, J.N., 2011b. The toxicity and effects in field by different pesticides to Acleris fimbirana Thunberg. Xingjiang agric. Sci., 48: 2046-2049.

Zhao, J.L., Wu, Y.P., Su, T.J., Jiang, G.F., Wu, C.S. and Zhu, C.D., 2016. The complete mitochondrial genome of Acleris fimbriana (Lepidoptera: Tortricidae). Mitochondr. DNA, 25: 1-3. https://doi. org/10.3109/19401736.2014.982625 